\title{
Mass Spectroscopic Evaluation of Virgin Olive Oils (VOOs) Fatty Acid Profile in terms of Cultivar, Geographical Origin, Extraction and Packaging Type
}

\author{
Didar Ucuncuoglu 1 ,a,* \\ ${ }^{I}$ Department of Food Engineering, Faculty of Engineering, Çankırı Karatekin University, 18100 Çankırı, Turkey \\ *Corresponding author

\begin{tabular}{l|l}
\hline A R T I C L E I N F O & A B S T R A C T \\
\hline & Ensuring the olive oil quality and authenticity has become a great importance for both traditional
\end{tabular} \\ Research Article \\ and emerging olive oil producing countries. The chemical composition in olive oil heavily varies \\ depending on the olive cultivar and its growing region, the agronomic applications, the olive oil \\ production methods and the process and storage conditions. With the help of some analytical \\ Received : 16/01/2019 \\ Accepted : 15/04/2019 \\ techniques and data evaluation methods, it is possible to grade olive oils in terms of their differences. \\ This research examines particularly fatty acid composition of commercial olive oils (2017/2018 \\ season) with mass detector coupled with gas chromatography (GC/MS). Results were evaluated for \\ grading of them according to IOC regulations based on cultivar (ripe or unripe Ayvalik and \\ Memecik), production (organic, stone mill, cold press, two or more centrifugation systems, filtered \\ Keywords: \\ Grading \\ or unfiltered) and packing type (transparent or dark glass bottle and plastic bottle), and also their \\ Olive Oil \\ Fatty Acid Profile \\ GC/MS \\ Mass Selective Detector \\ geographic origin (Ayvalik and Edremit towns, the Cunda Island, North Aegean region or South \\ Aegean Region). According to overall data processing, virgin olive samples could be successfully \\ distinguished in terms of theirs geographic origin and cultivar roots. Moreover, it was also explained \\ that the effect of process and package type for grading of olive oils as 'extra virgin' or 'virgin'.
}

\begin{tabular}{l}
\hline a.emir.57@gmail.com \\
\end{tabular}

\section{Introduction}

Virgin olive oils are extracted from fresh olive fruits (Olea europaea L.) using only mechanical and physical processes such as milling, olive paste mixing and centrifugation, and oil settling. It has high commercial interest due to its healthy and sensorial quality and highly prized for its contribution to the basic Mediterranean diet. Like elsewhere around the Mediterranean, olive oil is a very important foodstuff in Turkey and takes pride of place in Turkish cuisine. By the 2017/2018 season, 2100000 tonnes olive were cultivated and 1640000 tonnes of this were processed into the olive oil (TSI, 2019).

The International Olive Council (IOC, 2019) regulation defines three categories for olive oils based on their free acidity namely extra virgin, virgin and ordinary virgin olive oil. The acidity value of oils was influenced by several factors such as variety, method of harvesting, extraction process, packing and storage conditions (Tsimidou et al., 2005). Peroxide value, $K_{232}$ and $K_{270}$ specific absorbance and fatty acid composition are the other quality and purity parameters used for grading of olive oils. Overall quality of olive oil is also affected by many factors. These factors include the cultivar and extraction process (Di Giovacchino et al, 1994), the climatic conditions during the production year and the geographic production area (Vichi et al, 2003; Temime et al, 2006). Many analytical techniques can be used for measuring or detecting those parameters.

In the last decade, gas chromatography coupled to mass spectrometer (GC/MS) is increasingly used because of the power of MS in structural data studies (Ecker et al, 2012; Alves et al., 2016). Particularly, mass spectroscopy is mainly utilized for characterization (Lara-Ortega et al., 2018) of olive oil in terms of detecting adulterant (Lorenzo et al, 2002; Alves et al, 2013) or authenticates the specific compounds (Angerosa et al., 1996; Vaclavik et al., 2009), i.e. phenolic and secoiridoid aglycons, or geographic origin (Casale et al., 2012; Persuric et al., 2018).

Over the recent decades, the guarantee of olive oil quality and authenticity has become a great importance to consumers, suppliers, retailers, and regulators in both traditional and emerging olive oil producing countries, mainly due to the upgrading worldwide obtained popularity and the trade globalization of virgin olive oils (Bajoub et al., 2018). Mostly, in Turkey, olive oil is extracted via stone mill production, cold press or centrifugation systems. They can be filtered or unfiltered. Olive oils packed in transparent or dark plastic or glass bottles and different volumes of tin cans. This research 
examines particularly fatty acid composition of commercial high quality Ayvalik and Memecik olive oils with mass detector (MS) coupled with gas chromotography (GC). Results were evaluated for grading of them according to cultivar, production and packing type, and also their geographic origins. The commercial olive oil samples were collected at 2017-2018 harvest season and total free acidity, peroxide value and fatty acid profile with mass detection were discussed in detail.

\section{Materials and Methods}

\section{Materials}

The commercial olive oil samples analysed in this study was collected from local boutique stores on March after 2017/2018 harvest season (October-November). As shown at Table 1, olive cultivars (Ayvalik and Memecik), olive types (organic, ripe or unripe), theirs geographic origins (Ayvalik, Cunda and Edremit towns, North and South Aegean Regions), oil processing type (cold press, filtered or unfiltered) and packing material (transparent or dark glass bottle and plastic bottle) were different, their brands were kept secret, so, they were signed as A, B, C, D and E. Three random bottles for each brand package were used and each oil sample bottle was analysed in triplicate $(3 \times 3$ $\times 16, \mathrm{n}: 144)$.

\section{Methods}

Total free acidity (FFA, as percentage of oleic acid) and peroxide value (PV, as milliequivalents of active oxygen per kilogram of oil) parameters were determined. All analyses were measured in triplicate according to standard methods declared in the European Union Commission Regulation EEC 2568 (1991) and its later amendments.

The fatty acid methyl esters (FAMEs) were prepared according to the International Olive Council's method (COI/T.20/Doc. No. 24, 2001), and were analysed by the Agilent-Technologies GC equipped with 6890 N Network GC system containing an Agilent-Technologies 5975 inert XL Mass Selective Detector (MSD) and Agilent autosampler 7683-B injector (Agilent technologies, Little Falls, NY, USA). The FAMEs were separated on AgilentTechnologies capillary column HP-5 MS (5\% phenyl methylsiloxane) with dimension of $30 \mathrm{~m} \times 0.25 \mathrm{~mm}$ i.d. $\times$ $0.25 \mu \mathrm{m}$ film thickness. A sample volume of $1.0 \mu \mathrm{L}$ was injected into the column using the split mode (split ratio 100:1). The carrier gas used was helium at a flow rate of $1.0 \mathrm{~mL} \cdot \mathrm{min}^{-1}$. Initial oven temperature was $60{ }^{\circ} \mathrm{C}$, then, 3 ${ }^{\circ} \mathrm{C} / \mathrm{min}$ to $200{ }^{\circ} \mathrm{C}$ for $20 \mathrm{~min}$ and finally $3{ }^{\circ} \mathrm{C} / \mathrm{min}$ to 270 ${ }^{\circ} \mathrm{C}$ for $30 \mathrm{~min}$. The scanning mass range varied from 50 to $550 \mathrm{~m} / \mathrm{z}$. All measurements were triplicated. This method was originated from Anwar et al. (2010) with small modifications. The GC-MS apparatus was linked to a PC running software for data acquisition and processing. Under the GC-MS conditions used, FAMEs eluted in order of increasing molecular weight and, for a given molecular weight, in order of decreasing saturation. The fatty acid composition was reported below as a relative percentage. The identification of unknown fatty acid methyl esters (FAMEs) was performed by comparing their relative and absolute retention times with those of pure standards of FAMEs. FAMEs were further identified by comparing their MS spectra with those from the NIST mass spectral library of the GC/MS system. All chemicals were chromatographic grade (Sigma-Aldrich, Madrid, Spain).

Statistical analysis was performed by SPSS (version 23, IBM SPSS Statistics Inc. Chicago, IL) statistical software and using One-way ANOVA method. Differences among all groups were determined by Duncan and LSD test. All statistical analyses were performed at least duplicate.

\section{Results and Discussion}

Even though the information was written on label of package, FFA and PV were again determined due to discuss this study results exactly and correctly. Obtained analyse results were given in Table 2 . It was observed that FFA and PV were changed between $0.45-0.93 \%$ and 3.9814.20 meq active $\mathrm{O} 2 / \mathrm{kg}$ oil, respectively. It was declared by Council of Higher Education Thesis Center (2019) from Turkey, according to newly accessed studies, Ayvalik and Memecik virgin olive oils FFA content ranged from $0.2 \%$ to $0.9 \%$ and PV ranged from 3.0 to 23.4 during 2012-2016 harvest seasons (Cevik, 2014; Ucuncuoglu, 2018). Thus, our results were parallel with those works.

Table 1 Sample descriptions

\begin{tabular}{|c|c|c|c|c|}
\hline SS & Brand & Label Information on Bottle & PM & GI \\
\hline 1 & A & Organic, Cold Press, GO: Aegean Region Originated, Cultivar: Ayvalik & Dark, Glass & No \\
\hline 2 & B. 1 & GO: Ayvalik town (North Aegean Region), Cultivar: Ayvalik & Dark, Glass & No \\
\hline 3 & C. 1 & Stone mill production, GO: Ayvalik town (North Aegean Region), Cultivar: Ayvalik & Dark, Glass & Yes \\
\hline 4 & C. 2 & Unfiltered cold press, GO: Ayvalik town (North Aegean Region), Cultivar: Ayvalik & Dark, Glass & Yes \\
\hline 5 & B.2 & Green, unripe olive extract, GO: Edremit town (North Aegean Region), Cultivar: Ayvalik & Transparent, Glass & No \\
\hline 6 & B.3 & Ripe olive extract, GO: Edremit town (North Aegean Region), Cultivar: Ayvalik & Transparent, Glass & No \\
\hline 7 & B. 4 & GO: Ayvalik town (North Aegean Region), Cultivar: Ayvalik & Dark, Glass & No \\
\hline 8 & B. 5 & GO: Cunda Island from Balikesir (North Aegean Region), Cultivar: Ayvalik & Dark, Glass & No \\
\hline 9 & B.6 & GO: Edremit town (North Aegean Region), Cultivar: Ayvalik & Dark, Glass & No \\
\hline 10 & B.7 & GO: North Aegean Region, Cultivar: Ayvalik & Dark, Glass & No \\
\hline 11 & B. 8 & GO: North Aegean Region, Cultivar: Ayvalik & Transparent, Glass & No \\
\hline 12 & B.9 & GO: South Aegean Region, Cultivar: Memecik & Transparent, Glass & No \\
\hline 13 & C. 3 & No info about cultivar and region & Plastic & No \\
\hline 14 & $\mathrm{D}$ & No info about cultivar and region & Plastic & No \\
\hline 15 & E.1 & Cold press, GO: South Aegean Region, Cultivar: Memecik & Transparent, Glass & No \\
\hline 16 & E.2 & Cold press, GO: North Aegean Region, Cultivar: Ayvalik & Transparent, Glass & No \\
\hline
\end{tabular}

SS: Sample Series, PM: Packaging Material, GI: Geographic Indication, GO: Geographic origin of virgin olive oil samples 
Table 2 Detected quality and purity parameters of commercial olive oils $(\mathrm{P}<0.01)$

\begin{tabular}{|c|c|c|c|c|c|c|}
\hline $\mathrm{S}$ & FFA & PV & C16:1 & $\mathrm{C} 17: 1$ & C18:1 & C20:1 \\
\hline 1 & $0.9 \pm 0.0^{\mathrm{AB}}$ & $6.5 \pm 0.5^{\mathrm{CD}}$ & $0.6 \pm 0.0^{\mathrm{B}}$ & nd & $75.0 \pm 0.1^{\mathrm{C}}$ & $0.3 \pm 0.0^{\mathrm{A}}$ \\
\hline 2 & $0.5 \pm 0.0^{\mathrm{I}}$ & $5.0 \pm 0.7^{\mathrm{EF}}$ & $0.6 \pm 0.0^{\mathrm{B}}$ & $0.1 \pm 0.0^{\mathrm{BC}}$ & $73.6 \pm 0.2^{\mathrm{DEF}}$ & $0.2 \pm 0.0^{\mathrm{ABC}}$ \\
\hline 3 & $0.8 \pm 0.0^{\mathrm{BC}}$ & $7.5 \pm 0.3^{\mathrm{CD}}$ & $0.7 \pm 0.1^{\mathrm{A}}$ & $0.1 \pm 0.0^{\mathrm{AB}}$ & $72.9 \pm 0.1^{\mathrm{FG}}$ & $0.2 \pm 0.0^{\mathrm{ABC}}$ \\
\hline 4 & $0.7 \pm 0.0^{\mathrm{CD}}$ & $13.0 \pm 0.9^{\mathrm{A}}$ & $0.5 \pm 0.1^{\mathrm{BC}}$ & $0.1 \pm 0.0^{\mathrm{AB}}$ & $72.7 \pm 0.2^{\mathrm{FG}}$ & $0.2 \pm 0.0^{\mathrm{ABC}}$ \\
\hline 5 & $0.6 \pm 0.0^{\mathrm{FG}}$ & $5.5 \pm 0.7^{\mathrm{DE}}$ & $0.5 \pm 0.0^{\mathrm{BCD}}$ & $0.2 \pm 0.0^{\mathrm{A}}$ & $73.4 \pm 0.0^{\mathrm{EFG}}$ & $0.3 \pm 0.0^{\mathrm{AB}}$ \\
\hline 6 & $0.6 \pm 0.0^{\mathrm{EF}}$ & $4.5 \pm 0.4^{\mathrm{EF}}$ & $0.5 \pm 0.0^{\mathrm{BCD}}$ & $0.2 \pm 0.0^{\mathrm{A}}$ & $73.4 \pm 0.0^{\mathrm{EFG}}$ & $0.3 \pm 0.0^{\mathrm{AB}}$ \\
\hline 7 & $0.6 \pm 0.0^{\mathrm{FG}}$ & $4.0 \pm 0.7^{\mathrm{FG}}$ & $0.4 \pm 0.1^{\mathrm{DE}}$ & $0.1 \pm 0.0^{\mathrm{D}}$ & $72.4 \pm 1.1^{\mathrm{G}}$ & $0.2 \pm 0.0^{\mathrm{BC}}$ \\
\hline 8 & $0.6 \pm 0.0^{\mathrm{FG}}$ & $7.5 \pm 0.4^{\mathrm{C}}$ & $0.5 \pm 0.0^{\mathrm{BCD}}$ & $0.1 \pm 0.0^{\mathrm{ABC}}$ & $74.3 \pm 1.5^{\mathrm{CDE}}$ & $0.3 \pm 0.1^{\mathrm{AB}}$ \\
\hline 9 & $0.6 \pm 0.0^{\mathrm{FG}}$ & $4.0 \pm 0.3^{\mathrm{G}}$ & $0.4 \pm 0.0^{\mathrm{DE}}$ & $0.1 \pm 0.0^{\mathrm{CD}}$ & $74.1 \pm 0.1^{\mathrm{CDE}}$ & $0.2 \pm 0.0^{\mathrm{C}}$ \\
\hline 10 & $0.6 \pm 0.0^{\mathrm{FG}}$ & $4.5 \pm 0.4^{\mathrm{EF}}$ & $0.4 \pm 0.0^{\mathrm{EF}}$ & nd & $74.5 \pm 0.7^{\mathrm{CDE}}$ & $0.2 \pm 0.0^{\mathrm{C}}$ \\
\hline 11 & $0.5 \pm 0.0^{\mathrm{HI}}$ & $4.0 \pm 0.7^{\mathrm{FG}}$ & $0.4 \pm 0.1^{\mathrm{E}}$ & $0.1 \pm 0.0^{\mathrm{D}}$ & $76.3 \pm 0.8^{\mathrm{B}}$ & $0.1 \pm 0.0^{\mathrm{D}}$ \\
\hline 12 & $0.7 \pm 0.0^{\mathrm{DE}}$ & $7.5 \pm 0.7^{\mathrm{C}}$ & $0.3 \pm 0.1^{\mathrm{FG}}$ & nd & $76.8 \pm 0.4^{\mathrm{B}}$ & $0.1 \pm 0.0^{\mathrm{D}}$ \\
\hline 13 & $0.8 \pm 0.0^{\mathrm{BC}}$ & $7.0 \pm 0.7^{\mathrm{C}}$ & $0.3 \pm 0.0^{\mathrm{G}}$ & nd & $78.1 \pm 0.4^{\mathrm{A}}$ & nd \\
\hline 14 & $0.9 \pm 0.0^{\mathrm{A}}$ & $10.0 \pm 0.3^{\mathrm{B}}$ & $0.3 \pm 0.0^{\mathrm{FG}}$ & nd & $78.0 \pm 0.5^{\mathrm{A}}$ & nd \\
\hline 15 & $0.5 \pm 0.00^{\mathrm{I}}$ & $4.0 \pm 0.7^{\mathrm{FG}}$ & $0.3 \pm 0.0^{\mathrm{FG}}$ & nd & $78.0 \pm 0.5^{\mathrm{A}}$ & nd \\
\hline 16 & $0.7 \pm 0.0^{\mathrm{EF}}$ & $7.0 \pm 0.7^{\mathrm{C}}$ & $0.7 \pm 0.3^{\mathrm{CDE}}$ & nd & $74.6 \pm 0.4^{\mathrm{CD}}$ & nd \\
\hline $\mathrm{S}$ & C18:3 \& C18:2 & C16:0 & C18:0 & C20:0 & C22:0 & \\
\hline 1 & $7.6 \pm 0.2^{\mathrm{E}}$ & $12.1 \pm 0.1^{\mathrm{G}}$ & $3.2 \pm 0.0^{\mathrm{A}}$ & $0.5 \pm 0.0^{\mathrm{A}}$ & $0.0 \pm 0.0^{\mathrm{C}}$ & \\
\hline 2 & $8.5 \pm 0.2^{\mathrm{D}}$ & $13.0 \pm 0.1^{\mathrm{DE}}$ & $2.9 \pm 0.1^{\mathrm{BCD}}$ & $0.4 \pm 0.0^{\mathrm{ABC}}$ & $0.2 \pm 0.0^{\mathrm{A}}$ & \\
\hline 3 & $7.4 \pm 0.2^{\mathrm{EF}}$ & $14.3 \pm 0.2^{\mathrm{A}}$ & $3.1 \pm 0.1^{\mathrm{AB}}$ & $0.4 \pm 0.0^{\mathrm{ABC}}$ & $0.1 \pm 0.0^{\mathrm{B}}$ & \\
\hline 4 & $9.1 \pm 0.0^{\mathrm{B}}$ & $13.6 \pm 0.0^{\mathrm{C}}$ & $2.8 \pm 0.1^{\mathrm{DE}}$ & $0.4 \pm 0.0^{\mathrm{BC}}$ & $0.1 \pm 0.0^{\mathrm{B}}$ & \\
\hline 5 & $9.0 \pm 0.1^{\mathrm{BC}}$ & $12.5 \pm 0.0^{\mathrm{F}}$ & $3.1 \pm 0.1^{\mathrm{AB}}$ & $0.5 \pm 0.0^{\mathrm{AB}}$ & $0.1 \pm 0.0^{\mathrm{B}}$ & \\
\hline 6 & $9.0 \pm 0.1^{\mathrm{BC}}$ & $12.5 \pm 0.0^{\mathrm{F}}$ & $3.1 \pm 0.1^{\mathrm{AB}}$ & $0.5 \pm 0.0^{\mathrm{AB}}$ & $0.1 \pm 0.0^{\mathrm{B}}$ & \\
\hline 7 & $9.5 \pm 0.4^{\mathrm{A}}$ & $13.0 \pm 0.1^{\mathrm{DE}}$ & $3.1 \pm 0.2^{\mathrm{ABC}}$ & $0.4 \pm 0.1^{\mathrm{BC}}$ & $0.2 \pm 0.0^{\mathrm{A}}$ & \\
\hline 8 & $8.9 \pm 0.1^{\mathrm{BC}}$ & $13.2 \pm 0.0^{\mathrm{D}}$ & $2.0 \pm 1.5^{\mathrm{EF}}$ & $0.3 \pm 0.1^{\mathrm{DE}}$ & nd & \\
\hline 9 & $8.6 \pm 0.0^{\mathrm{CD}}$ & $13.0 \pm 0.0^{\mathrm{DE}}$ & $2.8 \pm 0.0^{\mathrm{DE}}$ & $0.4 \pm 0.01^{\mathrm{BCD}}$ & nd & \\
\hline 10 & $8.4 \pm 0.4^{\mathrm{D}}$ & $13.1 \pm 0.2^{\mathrm{DE}}$ & $2.9 \pm 0.1^{\mathrm{CD}}$ & $0.4 \pm 0.0^{\mathrm{CD}}$ & nd & \\
\hline 11 & $7.1 \pm 0.3^{\mathrm{FG}}$ & $12.9 \pm 0.1^{\mathrm{E}}$ & $2.6 \pm 0.1^{\mathrm{EF}}$ & $0.3 \pm 0.1^{\mathrm{EF}}$ & nd & \\
\hline 12 & $7.4 \pm 0.2^{\mathrm{EF}}$ & $12.6 \pm 0.2^{\mathrm{F}}$ & $2.5 \pm 0.1^{\mathrm{FG}}$ & $0.2 \pm 0.0^{\mathrm{EF}}$ & nd & \\
\hline 13 & $7.0 \pm 0.2^{\mathrm{G}}$ & $12.2 \pm 0.1^{\mathrm{G}}$ & $2.3 \pm 0.2^{\mathrm{G}}$ & $0.2 \pm 0.0^{\mathrm{F}}$ & nd & \\
\hline 14 & $7.0 \pm 0.2^{\mathrm{G}}$ & $12.1 \pm 0.1^{\mathrm{G}}$ & $2.4 \pm 0.1^{\mathrm{FG}}$ & $0.2 \pm 0.0^{\mathrm{EF}}$ & nd & \\
\hline 15 & $7.0 \pm 0.2^{\mathrm{G}}$ & $12.1 \pm 0.1^{\mathrm{G}}$ & $2.4 \pm 0.1^{\mathrm{FG}}$ & $0.2 \pm 0.0^{\mathrm{EF}}$ & nd & \\
\hline 16 & $8.8 \pm 0.2^{\mathrm{BCD}}$ & $14.5 \pm 0.7^{\mathrm{B}}$ & $1.6 \pm 0.1^{\mathrm{I}}$ & nd & nd & \\
\hline
\end{tabular}

nd: not detected

Table 3 Some of quality and purity parameter of olive oils (IOC, 2019)

\begin{tabular}{ll|lc}
\hline Parameters & & Extra virgin olive oil & Virgin olive oil \\
\hline Quality & FFA (\% oleic acid) & $\leq 2.0$ \\
criteria & PV (meq active O2/kg oil) & $\leq 0.8$ & $\leq 20$ \\
\hline & Lignoceric acid (C24:0) & $\leq 20$ & $\leq 0.2$ \\
& Behenic acid (C22:0) & $\leq 0.2$ & $\leq 0.2$ \\
& Arachidic acid (C20:0) & $\leq 0.2$ & $\leq 0.6$ \\
& Stearic acid (C18:0) & $\leq 0.6$ & $0.5-5.0$ \\
& Heptadecanoic acid (C17:0) & $0.5-5.0$ & $\leq 0.3$ \\
& Palmitic acid (C16:0) & $\leq 0.3$ & $7.5-20.0$ \\
Purity & Myristic acid (C14:0) & $7.5-20.0$ & $\leq 0.05$ \\
& Eicosenoic acid (C20:1) & $\leq 0.05$ & $\leq 0.4$ \\
& Oleic acid (cis-C18:1) & $\leq 0.4$ & $55.0-83.0$ \\
& Heptadecenoic acid (C17:1) & $55.0-83.0$ & $\leq 0.3$ \\
& Palmitoleic acid (C16:1) & $\leq 0.3$ & $0.3-3.5$ \\
& Linolenic acid (C18:3) & $0.3-3.5$ & $\leq 1.5$ \\
& Linoleic acid (C18:2) & $\leq 1.5$ & $3.5-21.0$ \\
& Trans fatty acid content $(\%)$ (trans-C18:1) & $\leq 0.05$ & $\leq 0.05$ \\
& Trans fatty acid content $(\%)$ (trans-C18:2+trans-C18:3) & $\leq 0.05$ & $\leq 0.05$ \\
\hline
\end{tabular}

According to FFA values, Sample 1 (the organic one) and Sample 14 (plastic and transparent packed) were not qualified as "extra virgin". The increments of FFA might be caused approximately five month (between October and March) shelf life. On the other hand, all samples had lower $\mathrm{PV}$ values than $20 \mathrm{meq}$ active $\mathrm{O}_{2} / \mathrm{kg}$ oil. Therefore, it can be classified every sample as "virgin" according IOC (2019) described in Table 3. As also shown at Table 2, there was a good classification $(\mathrm{P}<0.01)$ between cold press virgin olive oils which were collected South Aegean region (Memecik cultivar, Sample 15) and North Aegean region (Ayvalik cultivar, Sample 16) both FFA and PV. 
Sample 11 and 12 was packed in a transparent glass bottle, but their origin and cultivar were different. Sample 12 (Memecik cultivar) had significant difference $(\mathrm{P}<0.01)$ from Sample 11 (Ayvalik cultivar) and higher FFA and PV than Sample 11. Plastic bottled olive oils (Sample 13 and 14) and unfiltered olive oil (Sample 4) had much more high values in terms of both FFA and PV. B brand samples, namely 7-10, were packed dark glass bottle, were the same cultivar (Ayvalik), but their geographic origin were different. According to FFA statistics, they could not be classified $(\mathrm{P}>0.05)$; however, the highest $\mathrm{PV}$ was found at Sample 8 originated from Cunda Island. There was no significant difference $(\mathrm{P}>0.05)$ between Sample 5 and 6 (unripe and ripe type of olive) in terms of both FFA and PV.

Fatty acids are the main constituents of olive oil forming part of TAGs molecules. Olive oil is mostly characterized by the predominance of monounsaturated (in particular, oleic acid), the low percentage of saturated and a very low percentage of polyunsaturated fatty acids. As shown at Table 2, detected FAMEs were palmitoleic acid (C16:1), palmitic acid (C16:0), margoleic acid (C17:1), margaric acid (C17:0), linoleic acid (C18:2), linolenic acid (C18:3), oleic acid (C18:1-cis), stearic acid (C18:0), eicosenoic acid (C20:1), arachidic acid (C20:0), behenic acid (C22:0), respectively. The polyunsaturated fatty acids ( $\sum$ PUFA, linoleic acid and linolenic acids) were given as sum of theirs contents in Table 2. A former study (Diraman \& Hış1, 2003) explained that HP-5 column with GC-FID can discriminate major fatty acids but cannot give C18:2 \& C18:3 fatty acids separately and trans-forms of fatty acids. That's why C18:2 and C18:3 fatty acids percentages were given as "total amount" in this paper. Detected fatty acid methyl esters, except for C17:0, were significantly altered $(\mathrm{P}<0.01)$ between samples. Among all of the samples analysed, the values of the each fatty acid content fell within the ranges established for "virgin olive oil". The virgin olive oils extracted from Ayvalik cultivar contained 13.0\% C16:0; 0.5\% C16:1; 2.7\% C18:0; 74.5\% C18:1; 8.3\% \&PUFA; 0.4\% C20:0; 0.1\% C20:1 and 0.1\% C22:0, respectively. The virgin olive oils extracted from Memecik cultivar contained $12.4 \% \mathrm{C} 16: 0 ; 0.3 \% \mathrm{C} 16: 1 ; 2.5 \% \mathrm{C} 18: 0$; 77.4\% C18:1; 7.2\% \&PUFA; 0.2\% C20:1 and 0.2\% C22:0, respectively. There were several results about fatty acid composition of Turkish monoculture olive oils but they were mostly detected by GC and flame ionization detector (FID). A recent published research explained that the fatty acid profile differences of Ayvalik virgin olive oils based on geographical origin and harvest years. It was expressed that values varied over the three harvest years due to atmospheric conditions and particularly, C18:0, C18:1 and C18:2 values were different among origins $(\mathrm{p}<0.05)$ (Ucuncuoglu, 2018). Another research determined the fatty acid profile of Ayvalik olive oils that C16:0, C16:1, C18:0, C18:1, C18:2 were found 14\%, $0.02 \%, 2 \%, 68 \%$ and $11 \%$, respectively (Goldeli, 2015). On the other hand, "mass detection" enabled identification of structural isomers of C16:1 and C18:1, in particular. Such information about positional isomers of fatty acid differentiation in $\mathrm{C} 16$ and C18 provides a better understanding of the olive oil chemical composition (Laroussi-Mezghani et al., 2016). A typical fatty acid chromatogram was given in Figure 1 obtained by HP5-MS capillary column. There could be accessed really limited paper about fatty acid profile using Mass Selective Detector in virgin olive oils and none of them about commercial virgin olive oils. For example, fourteen fatty acid methyl esters were detected in Croatian olive oil samples by use of GC-MS. C16:0, C16:1, C17:0, C17:1, C18:0, C18:1, C18:1, C18:2, C18:3, C20:0, C20:1, C22:0, C24:0 fatty acids were confirmed in this study with -cis and -trans positional structure (Peršurić et al., 2018). Sample 12 and Sample 15 were distinguished in terms of C16:0, C18:1 and polyunsaturated fatty acid content. These samples were originated same cultivar (Memecik) and packed same type in transparent glass bottle; however, one of them was produced using cold press technique. Therefore, it would be deduced that C16:0, C18:1 and $\sum$ PUFA content were affected by oil production method. When the geographically indicated olive oils (Sample 3 and 4) compared, it was observed that C16:0, C18:0, C16:1 and $\sum$ PUFA values were significantly $(p<0.01)$ different. It could be checked that their cultivar (Ayvalik), geographic origin (Ayvalik town) were same; but, their production methods were different (stone mill production and unfiltered). Sample 15 and Sample 16 were distinguished in terms of all detected FAMEs. These samples were genetically originated different olive cultivar (Memecik and Ayvalik). On the other hand, their package and production type were same (transparent glass bottle and cold press). Sample 15 contained $78 \%$ oleic acid and $7 \%$ \&PUFA. Since, Sample 16 contained $74.6 \%$ oleic acid and $8.8 \%$ ¿PUFA. If the B brand olive oils (Sample 2, 7, 8 and 9), bottled at dark glass and extracted same cultivar (Ayvalik), were compared based on olives geographic origin, it could be detected that Sample 7 (Ayvalik town) was significantly different $(\mathrm{P}<0.01)$ in terms of both lower oleic acid (72.4\%) and higher $\sum$ PUFA (9.5\%) content. On the other hand, Ayvalik (Sample 7) and Edremit (Sample 9) town olive oil were clearly separated in terms of C18:0, and at the same time, Ayvalik (Sample 7) and Cunda Island (Sample 8) olive oil were also separated in terms of C20:0. If the B brand virgin olive oils (Sample 11 and 12), bottled in transparent glass, were compared based on olives cultivar, it could be observed that olives oils had different class statistically $(\mathrm{P}<0.01)$ in terms of both $\mathrm{C} 16: 0$ and C16:1 content. Same results were obtained Sample 15 and 16 . There was no significant difference $(\mathrm{P}>0.05)$ between Sample 5 and 6 in terms of their fatty acid profile. Theirs cultivar, extraction and packing type was same; but, harvest time was different (unripe-green and ripe olives). The organic olive oil, namely Sample 1, was clearly separated $(\mathrm{P}<0.01)$ from the other samples in terms of all fatty acid contents except for C16:1. Combined analytical technique and chemometrics were preferred in previous studies to discriminate virgin olive oils quality in terms of cultivar (Aranda et al., 2004; Agozzino et al., 2010; RuizSamblas et al., 2011), growing area (Diraman et al., 2010, 2011; Riccio et al., 2011).

\section{Conclusion}

Presented paper showed that the fatty acid profile of virgin olive oils has different quality (organic, package types, extraction types, cultivar and geographic origin) with mass selective detection coupled gas chromatography. Statistical analysis proved that C16:0, C18:1 and $\sum$ PUFA 
content were appropriate for grading the variation of commercial olive oil brands. It was determined that free acidity and peroxide value were changed between 0.45 $0.93 \%$ and $3.98-14.20$ meq active $\mathrm{O}_{2} / \mathrm{kg}$ oil. The oils extracted from Ayvalik cultivar contained 16.2\% total saturated fatty acid ( $\sum$ SFA), $75.3 \%$ total monounsaturated fatty acids ( $\sum$ MUFA) and $8.3 \%$ total polyunsaturated fatty acids ( $\sum$ PUFA). On the other hand, the oils extracted from Memecik cultivar contained $15.1 \% \quad$ SSFA, $77.8 \%$ $\sum$ MUFA and $7.2 \%$ PUFA. There were no trans- fatty acid form was detected with HP-5 capillary column in virgin olive oils. Mediterranean and European countries, which are major suppliers of olive oils on the world market, have adopted common regulations to protect olive oil growers and consumers from food adulterations and fraud. The authenticity of virgin olive oils covers many aspects, including genetic variety, geographical origin and quality grade. In this research, analytical profiling of fatty acids using GC-MS technique was tested in grading commercial olive oil's category. Statistical analysis showed a good classification power for virgin olive oils' geographical origin and cultivar.

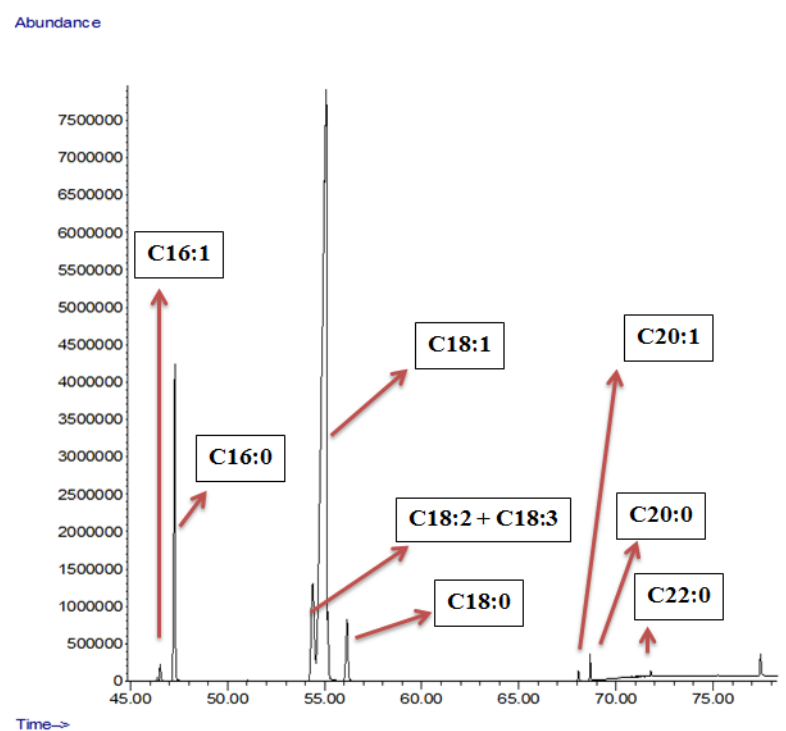

Figure 1 A typical chromatogram for virgin olive oil obtained by HP5-MS capillary column

\section{Acknowledgement}

We greatly appreciate access to equipment in possession of Namik Tanik Research Institute, University of Cankiri Karatekin. Special thanks to Department of Chemistry academic staffs.

\section{References}

Agozzino P, Avellone G, Bongiorno D, Ceraulo L, Indelicato,S, Indelicato S, Vekey K. 2010. Determination of the cultivar and aging of Sicilian olive oils using HPLC-MS and linear discriminant analysis. J. Mass. Spectrom. 45: 989-995. https://doi.org/10.1002/jms.1791

Alves E, Melo T, Rey F, Moreira ASP, Domingues P, Domingues MR. 2016. Polar lipid profiling of olive oils as a useful tool in helping to decipher their unique fingerprint. LWT-Food Science and Technology, 74: 371-377. https://doi.org/ 10.1016/j.lwt.2016.07.071
Alves JO, Botelho BG, Sena MM, Augusti R. 2013. Electrospray ionization mass spectrometry and partial least squares discriminant analysis applied to the quality control of olive oil. Journal of Mass Spectrometry, 48:1109-1115. https://doi.org/10.1002/jms.3256

Angerosa F, Di Giacinto L, Vito R, Cumitini S. 1996. Sensory evaluation of virgin olive oils by artificial neural network processing of dynamic head-space gas chromatographic data. Journal of Science Food and Agriculture, 72,323-328. https://doi.org/10.1002/(SICI)1097-0010(199611)72:3<323: AID-JSFA662>3.0.CO;2-A

Anwar F, Rashid U, Ashraf M, Nadeem M. 2010. Okra (Hibiscus esculentus) seed oil for biodiesel production. Applied Energy 87 779-785. https://doi.org/10.1016/j.apenergy.2009.09.020

Aranda F, Gomez-Alonso S, Rivera del Alamo RM, Salvador MD, Fregapane G. 2004. Triglyceride, total and 2-position fatty acid composition of Cornicabra virgin olive oil: Comparison with other Spanish cultivars, Food Chemistry, 86, 485-492. https://doi.org/10.1016/j.foodchem. 2003.09.021

Bajoub A, Medina-Rodriguez S, Ajal E, Cuadros-Rodriguez L, Monasterio RP, Vercammen J, Fernandez-Gutierrez A, Carrasco-Pancorbo A. 2018. A metabolic fingerprinting approach based on selected ion flow tube mass spectrometry (SIFT-MS) and chemometrics: A reliable tool for Mediterranean origin-labeled olive oils authentication. Food Research International, 106:233-242. https://doi.org/10.1016 /j.foodres.2017.12.027

Casale M, Oliveri P, Casolino C, Sinelli N, Zunin P, Armanino C. 2012. Characterisation of PDO olive oil Chianti Classico by non-selective (UV-visible, NIR and MIR spectroscopy) and selective (fatty acid composition) analytical techniques. Analytica Chimica Acta, 712, 56-63. https://doi.org/ 10.1016/j.aca.2011.11.015

Cevik S. 2014. Naturel sizma zeytinyag1 aroma profili optimizasyonu, MSc Thesis, Food Engineering Department, Suleyman Demirel University, Isparta-Turkey. https://tez.yok.gov.tr/UlusalTezMerkezi/giris.jsp [Accessed in January 2019]

Diraman H, Hisil Y. 2003. Gaz Kromatografisinde Farklı Polaritede İki Kapiler Kolon Kullanılarak Çeşitli Yağlardaki Yağ Asitlerinin Cis-Trans İzomerlerinin Analizi. Gıda, 28 (8): 513-521 http://dergipark.gov.tr/gida/issue/6978/93009

Diraman H, Saygi H, Hisil Y. 2010. Relationship Between Geographical Origin and Fatty Acid Composition of Turkish Virgin Olive Oils for Two Harvest Years. J Am Oil Chem Soc, 87:781-789. https://doi.org/10.1007/s11746-010-1557-2

Diraman H, Saygi H, Hisil Y. 2011. Classification of three Turkish olive cultivars from Aegean region based on their fatty acid composition. European Food Research Technology, 233: 403-411. https://doi.org/10.1007/s00217-011-1511-z

Di Giovacchino L, Solinas M, Miccoli M. 1994. Effects of extraction systems on the quality of virgin olive oil. Journal of American Oil and Chemical Society, 71, 1189-1194. https://link.springer.com/content/pdf/10.1007\%2FBF025405 35.pdf [Accessed in January 2019]

Ecker J, Scherer M, Schmitz G, Liebisch G. 2012. A rapid GCMS method for quantification of positional and geometric isomers of fatty acid methyl esters. Journal of Chromatography B, 897, 98-104. https://doi.org/10.1016 /j.jchromb.2012.04.015

EEC. 1991. European Union Commission, Characteristics of olive oil and olive-residue oil and relevant methods of analysis. Commission regulation EEC/2568/91 as amended. Official Journal of the European Communities, L248, 1-83.

Goldeli T. 2015. The effects of different holding types and times on quality attributes of oil obtained from olives belonging to Akhisar region, MSc Thesis, Food Engineering Department, Celal Bayar University, Manisa-Turkey. https://tez.yok.gov.tr /UlusalTezMerkezi/giris.jsp [Accessed in January 2019] 
IOC. 2001. International Olive Council. Trade Standard Applying to Olive Oil and Olive Pomace Oil. In COI/T.20/Doc. No. 24

IOC. 2019. International Olive Council, http://www.internationaloliveoil.org [Accessed in April 2019]

Lara-Ortega FJ, Beneito-Cambra M, Robles-Molina J, GarcíaReyesa JF, Gilbert-López B, Molina-Díaz A. 2018. Direct olive oil analysis by mass spectrometry: A comparison of different ambient ionization methods, Talanta, 180, 168-175. https://doi.org/10.1016/j.talanta.2017.12.027

Laroussi-Mezghani S, Le Dreau Y, Molinet J, Hammami M, Grati-Kamoun N, Artaud J. 2016. Biodiversity of Tunisian virgin olive oils: varietal origin classification according to their minor compounds. European Food Research and Technology, 242:1087-1099. https://doi.org/10.1007/s00217 $-015-2613-9$

Lorenzo IM, Pavon JLP, Laespada EF, Pinto CG, Cordero BM. 2002. Detection of adulterants in olive oil by headspace-mass spectrometry, Journal of Chromatography A, 945, 221-230. https://doi.org/10.1016/S0021-9673(01)01502-3

Mass Spectral Library, 2019. https://www.nist.gov [Accessed in April 2019]

Peršurić Ž, Saftića L, Mašek T, Kraljević Pavelića S. 2018. Comparison of triacylglycerol analysis by MALDI-TOF/MS, fatty acid analysis by GC-MS and non-selective analysis by NIRS in combination with chemometrics for determination of extra virgin olive oil geographical origin. A case study. LWT - Food Science and Technology 95. 326-332. https://doi.org/ 10.1016/j.lwt.2018.04.072

Riccio MF, Sawaya ACHF, Abdelnur PV, Saraiva SA, Haddad R, Eberlin MN, Catharino RR. 2011. Easy Ambient SonicSpray Ionization Mass Spectrometric of Olive Oils: Quality Control and Certification of Geographical Origin, Analytical Letters, 44: 1489-1497. https://doi.org/10.1080/00032719. 2010.512688 .
Ruiz-Samblas C, Cuadros-Rodriguez L, Gonzalez-Casado A, Rodriguez Garcia FP. 2011. Multivariate analysis of HT/GC(IT)MS chromatographic profiles of triacylglycerol for classification of olive oil varieties. Anal Bioanal Chem. 399(6):2093-103. https://doi.org/10.1007/s00216-010-4423-z

Temime SB, Campeol E, Cioni PL, Daoud D, Zarrouk, M. 2006. Volatile compounds from Chétoui olive oil and variations induced by growing area. Food Chemistry, 99 (2): 315-325. https://doi.org/10.1016/j.foodchem.2005.07.046

TSI. 2019. Turkish Statistical Institute, http://www.turkstat.gov.tr/Start.do [Accessed in January 2019]

Tsimidou ZM, Georgiou A, Koidis A, Boskou D. 2005. Loss of stability of "veiled" (cloudy) virgin olive oils in storage. Food Chem, 93: 377- 383. https://doi.org/10.1016/j.foodchem. 2004.09.033

Ucuncuoglu D. 2018. Characterization of Ayvalik (Edremit Yaglik) extra virgin olive oils volatile compounds with SPME-GC/MS and Raman spectroscopy, PhD Thesis, Food Engineering Department, Hacettepe University, AnkaraTurkey. https://tez.yok.gov.tr/UlusalTezMerkezi/giris.jsp [Accessed in January 2019]

Vaclavik L, Cajka T, Hrbek V, Hajslova J. 2009. Ambient Mass Spectrometry Employing Direct Analysis in Real Time (DART) Ion Source for Olive Oil Quality and Authenticity Assessment. Analytica Chimica Acta 645(1-2): 56-63. https://doi.org/10.1016/j.aca.2009.04.043

Vichi S, Pizzale L, Conte LS, Buxaderas S, Lopez-Tamames E. 2003. Solid-phase microextraction in the analysis of virgin olive oil volatile fraction: Characterization of virgin olive oils from two distinct geographical areas of northern Italy. Journal of Agricultural and Food Chemistry, 51, 6572-6577. https://doi.org/10.1021/jf030269c 